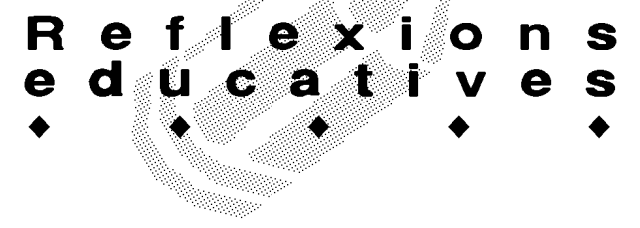

\title{
LA INHIBICIÓ INTEL-LECTUAL I LES SEVES MANIFESTACIONS A L'ESCOLA: UNA IL-LUSTRACIÓ CLÍNICA
}

\author{
M. Dolores Hierro i Inés Tomás. Àrea de Personalitat, Avaluació i Tractament Psicològic
}

La mare de la Laia, (aquest es un nom que no correspon al real), arriba a la consulta, amb una demanda molt explícita: «Volem saber el nivell intel-lectual de la nena. Si veiem que és curteta, ja ens quedarem tranquils...»

Davant l'interrogant de la psicòloga, afegeix tot un seguit de comentaris respecte al rendiment escolar de la seva filla: Ha repetit dos cursos de l'ensenyament primari i continua suspenent la major part de les assignatures. Segons la mare, els problemes amb l'aprenentatge ja van comencar a preescolar, on no seguia el ritme dels seus companys quan se'ls comencava a transmetre colors, formes i nombres.

Ella se n'ha adonat des del principi, perquè té un altre fill dos anys més gran que la Laia, que havia tingut una evolució molt més ràpida que la nena quant a assimilació de coneixements, però no hi havia donat gaire importància, perquè tothom li havia dit que el seu fill era molt intel-ligent.

La introducció d'aquest element a l'entrevista ens permet preguntar per aspectes de l'ambient i situació familiar, i aquests són els trets més rellevants:

- El pare té quaranta anys i la mare, trenta-cinc. Tots dos tenen formació universitària, si bé la mare va interrompre els seus estudis al casar-se. Tot i així, va treballar als primers anys de matrimoni, ajudant en la feina que té el seu marit, però ho va deixar fa set anys, al quedar embarassada del tercer fill, que és una nena.

- Comenta que la Laia surt molt amb aquesta germana petita de sis anys, i que s'ho passa molt bé traient-la a passejar, donant-li el menjar, vestint-la i, en definitiva, fent-li una mica de mamà.

De fet assegura que a la Laia li agraden molt totes aquestes tasques domèstiques, i que és l'únic per al que serveix i que la fa bellugar. Fins $i$ tot li agrada molt fer ganxet com ho fa l'àvia materna, que tot sovint passa temporades amb ells.

Tret d'aquestes activitats, la Laia és, segons la mare, una nena molt apàtica, que es passaria tot el dia ajaguda veient pel-lícules, i a qui no li interessa res vinculat a l'escola.
- Durant el curs escolar es veuen poc perquè es queda a dinar al col.legi, com la resta dels fills, i ella i el seu marit tenent molta vida social; però a l'estiu van tots a una casa de platja on fan molta vida junts, exceptuant el pare, que és el gran absent familiar, ja que dedica tot el temps de què disposa a treballar.

La mare afegeix que el seu marit s'ocupa dels fills en l'aspecte material, però que ella això ho troba bé.

- Assegura que dins l'ambient familiar, la Laia no representa cap problema perquè, com ja ha quedat dit, li agraden molt totes les qüestions vinculades a la llar $\mathrm{i}$ també ocupar-se de sí mateixa en l'aspecte higiènic i d'aparença física.

L'únic que ha representat un problema per a la mare han estat els estudis. Al principi l'ajudava ella a fer els deures, però com que la nena no tenia cap interès, ni comprenia les tasques que havia de fer, ella es posava molt nerviosa i acabava indultant-la i comparant-la contínuament amb el germà. Això ha fet que finalment li digués que ella ja no podia ajudar-la més, i que busquessin una professora particular, amb qui fa els deures cada tarda.

- Com a dades rellevants de la seva infantesa, només pot dir el que ja ha comentat del seu comportament escolar des dels primers anys, i que és molt distreta, de tal manera que si li encarreguen, per exemple, que vagi a comprar alguna cosa, sempre torna a casa amb coses equivocades.

Per a la mare això també era un motiu de nerviosisme i ha acabat per no encarregar-li res. Diu que no la castiguen perquè creu que no serviria de res, ja que aquest és el caràcter de la Laia i això no es pot canviar.Tret de la problemàtica escolar, és una nena que si li deixen fer la seva, està sempre contenta. Només té por a la foscori per aquest motiu dorm sempre amb un llum encès.

D'altra banda, la mare assenyala que sempre s'ha entès més amb els professors que amb les professores i ha pensat que això podia ser degut al fet que els primers quatre anys de la Laia, com que ella treballava fora de casa, va estar canviant contínuament de "can- 


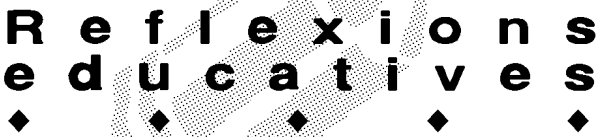

gurs". Al principi la nena mostrava la seva protesta per aquests fets, però al final, diu, ja s'hi va acostumar i no deia res.

Quan acaba d'explicar això, tot seguit i amb molt de nerviosisme diu que això són tonteries, i que si bé tots els professors li diuen que té capacitat suficient per rendir de forma adequada, ella està convençuda que la seva filla és "justeta", i el que han de fer és deixar-la tranquillla, però que ella se sentirà millor si això li confirma un professional, i que aquest és el motiu pel qual s'ha decidit a venir.

\section{Entrevista amb la Laia}

La Laia és, efectivament, una nena d'aspecte alegre i molt presumida. Diu que és aquí perquè estudia molt,

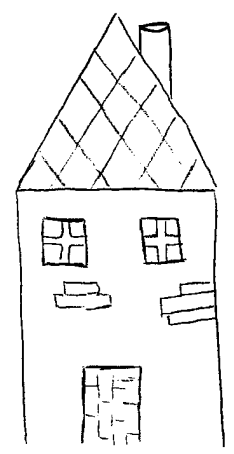

però tot li marxa del cap de seguida. Que no li entra res per més hores que es passi davant els llibres.

Assegura que s'ho passa molt bé a casa seva i al col-legi, encara que l'anglès i la llengua l'avorreixen.

Ara està molt contenta perquè fa un parell de dies que no es queda a dinar a l'escola, ja que el menjar no li agrada gens, i com que ho llençava tot i enredava molt, I'han expulsat d'aquest servei. Dina, doncs, a casa, amb la noia que fa les tasques domèstiques.

Preguntada sobre la seva capacitat, torna a contestar que hi ha assignatures que l'avorreixen i que a més es cansa d'estudiar perquè sap que, al cap d'una estona, ja no recordarà res. Diu que això li passa perquè només fa que pensar en el temps lliure i que li agradaria tenirne més per anar a jugar amb la seva germana, al cine amb les amigues i per a fer ganxet; i que a més ella no serveix per a estudiar.

Tenint en compte la demanda sorgida en aquestes entrevistes, passem a administrar la Escala de intel.ligència de Wechsler per a nens (WISC), i els resultats obtinguts es mostren a la taula 1.

La Laia obté, doncs, un coeficient intel-lectual (Cl), a través d'aquesta prova, de 113, la qual cosa es pot considerar normal-alt i que per tant no justifica per sí mateix, el baix rendiment escolar.

Però quan s'analitza separadament cada grup de puntuacions, a través de les seves mitjanes i desviacions típiques, observem que, malgrat l'aparent equilibri, a les puntuacions verbals, presenta les següents característiques:

- Informació i aritmètica donen una puntuació inferior a l'esperada i vocabulari está al límit, mentre que comprensió és superior a l'esperat.

Els resultats a Informació ens indiquen que, tot i el seu nivell intel.lectual, hi ha dificultats per a la memòria a llarg termini, la capacitat de comprensió i la del pensament associatiu.

Indica també pocs interessos per a la lectura iel món intel-lectual. Però a més és molt significatiu que hagi obtingut una puntuació tan baixa si la relacionem amb el seu $\mathrm{Cl}$. Total, ja que els nens amb un nivell d'in tel-ligència normal-alt donen també puntuacions altes en aquests ítems, quan això no succeeix així está correlacionat amb subjectes que viuen la possibilitat de saber com un fracàs. Que han tingut experiències prematures de fracàs en tasques senzilles, seguides d'èxit en algunes més complexes, la qual cosa els fa viure amb ansietat les situacions d'aprenentatge i manifesten hostilitat envers l'aprenentatge escolar.

Es pot tractar també de individus amb tendències perfeccionistes, que tendeixen a verbalitzar obsessivament les idees.

Aritmetica més baix de l'esperat, indica que hi ha dificultats per utilitzar conceptes numèrics abstractes $\mathrm{i}$

$\begin{array}{lcc} & \text { Puntuació } & \text { Puntuació } \\ \text { Prova } & \text { Directa (PD) } & \text { Típica (PT) } \\ \text { Informació } & 13 & 7 \\ \text { Comprensió } & 26 & 20 \\ \text { Aritmètica } & 10 & 8 \\ \text { Semblances } & 16 & 13 \\ \text { Vocabulari } & 55 & 9 \\ \text { Puntuació verbal } & & 57 \\ & & 13 \\ \text { Figures incompletes } & 11 & 23 \\ \text { Historietes } & 38 & 23 \\ \text { Cubs } & 48 & 59 \\ \text { Puntuació manipulativa } & & \\ & & \text { Coeficient } \\ \text { Puntuació total } & \text { Túpica (PT) } & \text { Intel-ligència (Cl) } \\ \text { Verbal } & 57 & 110 \\ \text { Manipulativa } & 59 & 114 \\ \text { Total escala } & 116 & \mathbf{1 1 3} \\ & & \end{array}$

Taula 1. Escala de intel-ligència de Wechsler per a nens (WISC). 


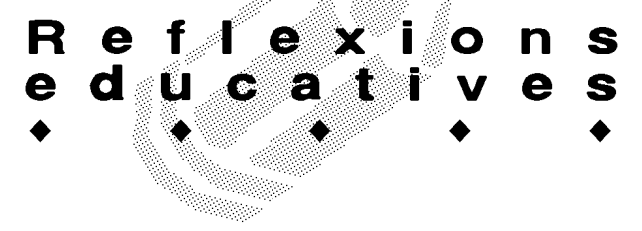

fer operacions, la qual cosa és una mesura del seu desenvolupament cognitiu.

Aquest és un ítem molt relacionat amb la capacitat mental d'un subjecte i la seva capacitat per assumir els coneixements que faciliten l'escola i les situacions de la vida ordinària.

Com passava amb Informació, no podem atribuir aquesta baixa puntuació al Cl d'aquesta noia i anant a la seva interpretació clínica, trobem que això ens indica distracció i atenció escassa, provocades per una ansietat que envaeix els processos de pensament; i una oposició davant les tasques proposades, així com conflictes emocionals i disfuncions en el contacte amb la realitat.

Comprensió més alt de l'esperat, és un indicador que hi ha bon sentit comú i un bon raonament. Té ben assimilats els coneixements socials convencionals i hi ha una organització superior del coneixement.

Per altra banda, i tenint en compte l'anàlisi fragmentada de les puntuacions obtingudes a la part manipulativa, cal assenyalar que hi ha puntuacions superiors a les esperades, a historietes i cubs, la qual cosa és indicadora de bona intel-ligència social i facilitat per analitzar, sintetitzar i reproduir dibuixos i situacions abstractes, així com una bona coordinació viso-manual i una bona orientació espacial.

\section{Conclusions en relació als resultats obtinguts amb la valoració del WISC}

Atenent els quadres gnoseològics des de la Interpretació Clínica del Wechsler, la Laia té capacitat suficient per a rendir intel/lectualment i assumir els coneixements que li pertoquen a nivell escolar, però hi ha una estructura histèrica de la personalitat que li impideix fer-ho.

Aquest psicodiagnòstic ens planteja que, tenint en compte l'estructura histèrica de la Laia, el mecanisme fonamental que ella utilitza per evitar els conflictes és la repressiói la negació. I quan aquests mecanismes són utilitzats d'una forma quantitativament excessiva, com és el cas, apareixen inhibicions i oblits no només davant d'allò que es vol evitar o negar, sinó en tota l'esfera cognitiva.

No han de sobtar-nos les seves dificultats d'atenció i concentració, ni els conseqüents problemes de memòria, quan hi ha tanta energia i tant d'esforç per a no veure ni entendre allò que li molesta i que li genera ansietat, un altre dels trets psicològics que, com hem vist, tan sovint apareix en aquest subjecte.

Després d'aquests resultats, vam considerar adequat obtenir informació adient mitjançant tècniques projectives gràfiques, que corroboressin aquestes hipòtesis de diagnòstic.

\section{Indicadors més rellevants obtinguts amb la valoració del HTP}

Tant el dibuix de la casa com el de l'arbre són situats a la vora del paper, sense línia base, la qual cosa és un indicador de falta de seguretat, necessitat de suport, por a l'acció.

A la casa, per altra banda, observem com els elements de relació social, com finestres i portes, són dibuixats per ràpidament tapar-los amb reixes $\mathrm{i}$ una mena de llambordes que impedirien aquesta relació.

És significatiu també el reforçament que fa del sostre i que indica por que les seves fantasies li facin perdre el control i el contacte amb la realitat. La història que verbalitza és de soledat, tant respecte a l'emplaçament de la casa com a la forma de vida dels que l'habiten.

L'arbre mostra, a més, cicatrius que indiquen la possible existència de situacions traumàtiques a la infantesa; i un element molt significatiu és que ella s'identifica amb el moixó que ocupa el niu que hi ha dibuixat, després de preguntar molt insistentment $\mathrm{i}$ amb molta sorpresa si podia pintar-hi tot el que volgués. Aquest és un indicador de regressió i necessitat de dependència i suport, que apareix un altre cop.

El tipus de rames que fa confirma el també observat al Wisc: Que té poques possibilitats d'èxit, però aquí apareix un element que obre les portes a l'esperança. Es tracta de les fruites que hi dibuixa i quan comenta el dibuix que ha fet, diu textualment: «Té aquesta marca rodona i les rames trencades, perquè l'havien podat per arreglar-lo, i ara està content perquè té vida que són les

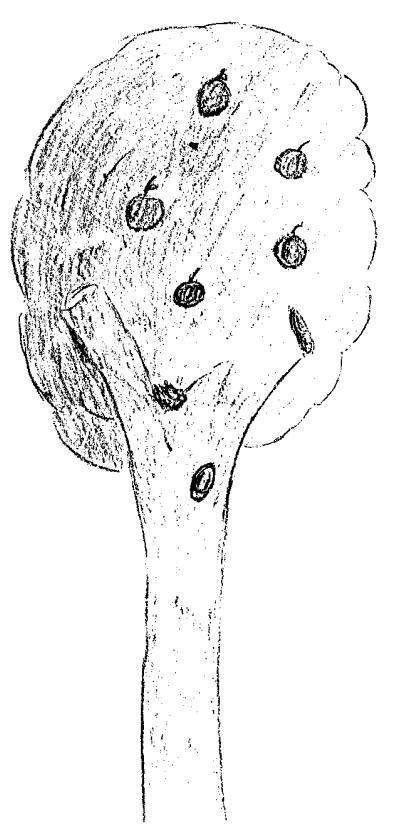




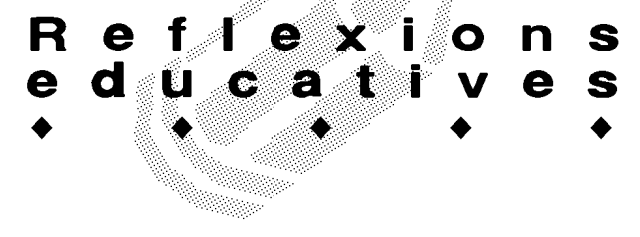

pomes aquestes, i podrà continuar creixent i donant fruits». Hi ha, per tant, una possibilitat de resoldre el seus conflictes.

Respecte als dibuixos de la figura humana, cal remarcar com a indicadors emocionals, el fet que amaguin la mà, la qual cosa assenyala que hi ha dificultats per al contacte, inhibicions, sentiments de culpa i necessitat de controlar l'agressió.

La nena va amb vestit uniformat, diu que és ella i que es tracta de l'uniforme del col-legi. S'està acomiadant i està contenta perquè l'han renyat per haver copiat un deure d'una companya, pero ara ja pot marxar a casa seva.

El nen és el germà gran. Comenta que és el que més mana a casa i que sempre la renya per com és de tonta.

Com a indicador emocional, en aquest cas, cal assenyalar la presència de dents, que indiquen agressivitat.

\section{Reflexions finals}

La Laia és un més d'aquells alumnes que hens trobem a les aules amb un fracàs escolar que no està correlacionat amb el seu nivell intel-lectual. Però no és aixó el més important, segons la nostra forma d'entendre un diagnòstic i les possibilitats d'intervenció en casos com aquest.

El més preocupant del tema és com detectar el que realment els passa a aquests subjectes. No és suficient passar una prova estandaritzada d'intel-ligència i treure'n conclusions en funció dels resultats numèrics. Es fa imprescindible una interpretació clínica d'aquests, refrendada, a més a més, per entrevistes amb els pares i el subjecte, perquè en una primera impressió no hi hauria, ni al Wisc, ni als gráfics, elements que ens permetessin pensar en aspectes psicopatològics d'aquesta nena.

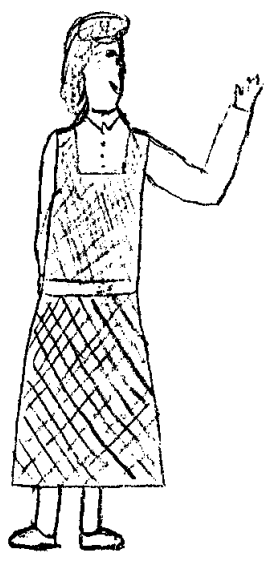

Aquest és un dels problemes més importants que cal enfrontar a l'hora d'establir un psicodiagnòstic: les proves estandaritzades només detecten anomalies, quan aquestes són ja considerables.

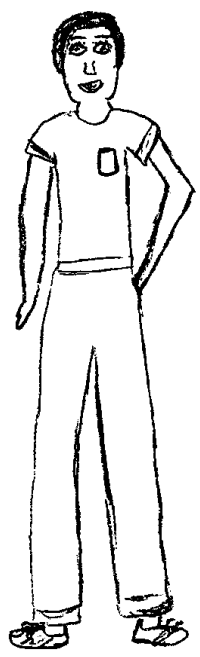

Però hem pogut fer patent, a través d'aquest cas, que la conflictiva neuròtica pot estar molts cops tapada, encoberta; tant pel mateix subjecte com per l'ambient que l'envolta. I una inadequada utilització dels mecanismes que tots necessitem per enfrontar-nos a la realitat $i$ a la seva problemàtica és suficient per generar simptomatologies als llocs més diversos i aparentment allunyats de la problemàtica.

La Laia no només necessita una professora que l'ajudi a fer els deures escolars. Necessita sentir, tenir, el dret que els adults que l'envolten es facin càrrec d'ella de debò. Necessita sentir, tenir, el dret a protestar dels abandonaments que ha sentit des de sempre. Necessita alliberar l'ansietat que li comporta el sentiment tan fort de soledat que té. En definitiva, necessita sentir i tenir el dret a no quedar-se amb aquest injust rol que se l'hi ha adjudicat: «és curteta, justeta, distreta».

\section{Bibliografia consultada}

FREUD, S. Obras Completas. Editorial Amorrortu. Buenos Aires. 1993.

GLASSER Y ZIMMERMAN. Interpretación Clínica de la Escala de Inteligencia de Wechsler, para niños. Ediciones Tea. Madrid. 1980.

$\mathrm{KOCH}, \mathrm{K}$. El Test del árbol. Editorial Kapelusz. Buenos Aires. 1992. 